\title{
Contraprestaciones por los servicios financieros del Consulado de México y sus miembros: los fondos extraordinarios para la guerra contra Gran Bretaña, 1779-1783
}

\author{
Guillermina Del Valle PavóN \\ Instituto de Investigaciones Dr. José María Luis Mora \\ gvalle@mora.edu.mx
}

Recepción: 21 de febrero de 2014 / Revisión: 23 de febrero de 2015

Aceptación: 9 de marzo de 2015 / Publicación: Diciembre de 2015

\begin{abstract}
RESUMEN
Nueva España aportó la mayor parte de los recursos que sostuvieron a las fuerzas armadas españolas durante la guerra contra Gran Bretaña que se desarrolló en el Caribe entre 1779 y 1783. En el artículo se analizan las medidas a las que recurrieron las autoridades reales para obtener recursos extraordinarios del Consulado y varios mercaderes de la ciudad de México. Asimismo se exponen algunas de las contraprestaciones que negociaron a cambio de dichos servicios financieros y se plantean diversas hipótesis acerca de los motivos económicos, sociales y políticos que los llevaron a colaborar con el monarca, teniendo en cuenta los negocios que realizaban durante el conflicto bélico y la forma en que eran afectados por la reciente apertura comercial.
\end{abstract}

Palabras clave: Fiscalidad, deuda pública, Real Hacienda, empréstitos, préstamos, donativos, contraprestaciones, mercaderes, consulados, guerras imperiales, México, siglo XVIII.

Compensation for the Financial Services of the Consulate of Mexico and its Members: Special Funding for the War against Great Britain, 1779-1783

\begin{abstract}
The Viceroyalty of New Spain contributed most of the economic resources that sustained Spain's military forces in the Caribbean during the Anglo-Spanish War, between 1779 and 1783 . This article analyzes the measures taken by the royal authorities in order to obtain extraordinary resources from the Consulate and various merchants of Mexico City, and it presents some of the compensations that were negotiated in exchange for said financial services. Various hypotheses are exposed regarding the economic, social and political motives that moved the merchants to collaborate with the Monarch, taking into account the negotiations carried out during the conflict, and the way in which they were affected by the recent commercial expansion.
\end{abstract}

Keywords: Taxation, Public Debt, Royal Treasury, Loans, Donations, Compensation, Merchants, Consulates, Imperial Wars, Mexico, 18th Century. 
Sumario: 1. Introducción. 2. La negociación de donativos. 3. Suplementos gratuitos de los mercaderes de México. 4. Intermediación financiera de los Tribunales del Consulado y de Minería. 5. Depósitos colocados a rédito en la Real Hacienda. 6. Conclusiones. 7. Referencias bibliográficas.

\section{INTRODUCCIÓN}

En 1779 Carlos III declaró la guerra a Gran Bretaña cuando luchaba contra la independencia de las Trece Colonias angloamericanas. Luego de haber padecido la captura de La Habana, en 1762, y la pérdida de Las Floridas, en 1763, el monarca dio prioridad absoluta a la contienda, con el objeto de restablecer la supremacía española en el Caribe, que se transformó en el teatro del conflicto. En razón del dinamismo que había adquirido la economía atlántica, los territorios de Hispanoamérica resultaban primordiales por la redefinición de su papel como colonias que debían beneficiar a la metrópoli a través de los intercambios. El ejército y la marina española además de fortificar las principales plazas de la región, lucharon por impedir el desembarco de los británicos en Cuba y reconquistar Las Floridas. Nueva España constituyó el principal soporte de las fuerzas armadas que se concentraron en el Caribe, al tiempo que mantuvo la transferencia de caudales a la Metrópoli, Filipinas y a otras posesiones de Indias. El apoyo que brindó la hacienda virreinal en dinero, víveres, armamentos y tropas resultó fundamental para sostener las campañas bélicas y la embestida contra los baluartes ingleses en Jamaica.

La historiografía española ha estudiado las medidas que adoptó el gobierno de Carlos III para mantener el conflicto bélico contra Gran Bretaña, se analizaron los instrumentos fiscales y financieros que se utilizaron para obtener caudales extraordinarios, así como los argumentos políticos que legitimaron su movilización ${ }^{1}$. Por lo que se refiere a Nueva España, se cuantificó el enorme apoyo financiero que otorgó para sostener la guerra en el Caribe, lo cual fue posible, en gran medida, por el incremento de los recursos fiscales que había resultado del programa de reformas impulsado luego de las derrotas de la Guerra de los Siete Años. Asimismo, se mostró el singular aumento que presentaron los ingresos de la hacienda virreinal por concepto de donativos, préstamos e impuestos de emergencia, a partir de $1780^{2}$. La obtención de recursos extraordinarios en Nueva España resultó fundamental, luego de que el Consulado de Cádiz trató de limitar las reformas comerciales recordando a las autoridades reales los préstamos que había otorgado y no habían sido restituidos ${ }^{3}$. Se analizaron las principales medidas tomadas por el virrey con el propósito de conseguir fondos extraordinarios para la guerra ${ }^{4}$; y cómo fueron los almaceneros de la ciudad de México y el Consulado en que se agrupaban, los principales contribuyentes de los donativos y suplementos gratuitos, mientras que los Tribunales del Consulado y de Minería fungieron como intermediarios financieros del erario virreinal ${ }^{5}$. Sin embargo, no se conoce quiénes fueron los mercaderes que facilita-

\footnotetext{
1 Para conocer el origen y desarrollo de la deuda pública de la dinastía de los Borbones y, en particular, de la que contrató Carlos III durante el ciclo bélico que se extendió de 1774 a 1783, véase ToRRES SÁnCHEZ, 2013.

2 Tepaske y Klein, 1986, vols. I y II; Klein, 1994, pp. 111-113; Grafenstein, 1997, pp. 136-141; Marichal, 1999, pp. 52-62.

3 Kuethe, 1999, pp. 63, 64.

4 Marichal, 1999, pp. 117-119.

5 Valle Pavón, 1997, pp. 157-208.
} 
ron sus caudales y consiguieron dinero a rédito de las personas y cuerpos que formaban parte de sus redes y, lo que es más importante, los beneficios que obtuvieron a cambio de los servicios financieros que brindaron a la monarquía.

El propósito del presente artículo radica en analizar a fondo las estrategias a las que recurrió el virrey Martín de Mayorga, entre 1780 a 1783, para conseguir recursos suplementarios del Consulado, los mercaderes de la ciudad de México y otras corporaciones, así como las principales contraprestaciones que obtuvieron a cambio de dichos servicios. Se examinan las medidas aplicadas por el virrey para obtener: 1) elevados donativos de los Tribunales del Consulado y Minería, así como de los principales almaceneros; 2) cuantiosos "suplementos" gratuitos de los comerciantes de la ciudad capital; y 3$)$ que los Tribunales del Consulado y Minería operaran como intermediarios financieros del erario para reunir dos empréstitos a réditos por un millón de pesos cada uno. Por último, veremos los esfuerzos que hizo el virrey para crear una deuda pública mediante la recepción a censo de los depósitos de los cuerpos judiciales y eclesiásticos, y cómo, ante la negativa del arzobispo de México a entregar los fondos de las corporaciones de su diócesis, se recurrió al Consulado. En cada caso se identifica a los principales contribuyentes, los negocios que realizaban, y se plantean varias hipótesis acerca de las contraprestaciones que negociaron a cambio de sus servicios financieros, teniendo en cuenta la forma en que eran afectados por la situación bélica y la apertura mercantil que cada vez adquiría mayores dimensiones. De acuerdo con la reciente historiografía sobre la construcción del Estado colonial y la capacidad de la metrópoli para extraer caudales en cantidades crecientes ${ }^{6}$, veremos cómo en el caso de la élite mercantil las autoridades reales recurrieron a la negociación para obtener recursos financieros extraordinarios en la ciudad de México, gran parte de los cuales se otorgaron de manera gratuita.

\section{LA NEGOCIACIÓN DE DONATIVOS}

Se ha estimado que, entre julio de 1779 y mediados de 1784, el virrey de Nueva España remitió a La Habana y otras posesiones del Caribe, entre poco más de 36 y cerca de 40 millones de pesos, al tiempo que mantuvo el suministró periódico de alimentos, armamentos y soldados 7 . El envío de enormes cantidades de dinero fue posible por la expansión de los productos fiscales que se presentó en Nueva España como consecuencia del incremento de la producción minera, así como por la aplicación de las reformas fiscales y comerciales, a las que el virrey Antonio María de Bucareli (1771-1779) había dado un fuerte impulso ${ }^{8}$. Sin embargo, los ingresos regulares del erario no alcanzaron para sostener los exorbitantes gastos generados por el conflicto, de modo que el virrey

\footnotetext{
6 IRIGOIN y Grafe, 2013.

7 Pueden verse las estimaciones de los diferentes autores y las hipótesis sobre las fluctuaciones en GRAFENSTEIN, 1997, pp. 137-141. Sobre el envío de caudales y diversos suministros al Presido del Carmen, Campeche, Yucatán, Honduras, Guatemala y Manila, pueden verse: De Mayorga a Cossío, México, 13 de febrero de 1782. AGN, Consulados, 306-7, fs. 6-7. ReAl DíAz y Heredia, 1968, pp. 114-121.

8 Según las estimaciones sobre el ingreso total de las rentas novohispanas, éste pasó de 12,4 millones de pesos en la década de 1760, a 17,5 millones en el siguiente decenio, y prácticamente se duplicó en los años ochenta al llegar a 31,8 millones de pesos. KLeIn, 1985, pp. 562-569; PÉreZ Herrero, 1988, p. 137-157.
} 
Martín de Mayorga decidió incrementar los derechos de alcabalas, almojarifazgos, pulque y el precio del tabaco, además de recurrir a los "sobrantes" de los ramos que solían remitirse a la Metrópoli, entre los que se destaca los del tabaco ${ }^{9}$. Estos fondos también resultaron insuficientes para soportar el enorme esfuerzo bélico, por lo que se tuvieron que demandar recursos adicionales a las principales corporaciones y a los vecinos más ricos de la ciudad de México, medida que, como veremos, tenía un mayor costo político.

Desde el ascenso de los Borbones los donativos y los empréstitos constituyeron una parte muy importante de la administración hacendaria porque proporcionaban liquidez de manera más o menos inmediata; sin embargo, presentaban el inconveniente de dar lugar al requerimiento de contraprestaciones. El Consulado de México había otorgado a la monarquía cuantiosos servicios financieros para apoyar los conflictos bélicos en que se veía envuelta, en compensación de los cuales había obtenido importantes beneficios de carácter fiscal y comercial ${ }^{10}$. En Nueva España, las primeras demandas de apoyo económico para sostener la guerra contra Gran Bretaña se plantearon en forma de donativos. En mayo de 1780, a iniciativa del Ministro de Indias, José de Gálvez, los tribunales del consulado y minería otorgaron donativos graciosos por cien mil pesos cada uno para las urgencias del Príncipe de Asturias. Por orden del monarca, Gálvez había solicitado a la Casa de los Cinco Gremios Mayores de Madrid -que había sido beneficiada con importantes privilegios de carácter financiero y comercial- que prestaran al príncipe de Asturias a corto plazo dos millones de reales de vellón -equivalentes a 200,000 pesos- los cuales serían restituidos por los mencionados tribunales de la ciudad de México. A principios de octubre, se enviaron los 200,000 pesos a Veracruz, en donde se embarcaron al puerto de Cádiz, consignados a la diputación de los Cinco Gremios Mayores ${ }^{11}$.

Todo parece indicar que los representantes de los mercaderes negociaron ventajosamente el donativo demandado por el Ministro de Indias. En octubre de 1780, unos días después de que se habían despachado a Cádiz los 100,000 pesos, consiguieron que el virrey, en lugar de imponer el derecho de alcabala de reventas para satisfacer las urgencias del erario, aumentara un 2\% a la alcabala ordinaria, sobre el $6 \%$ que entonces se exigía. Esta medida, que se denominó "indulto de la reventa", ${ }^{12}$ constituyó un gran beneficio para los mercaderes consulares, uno de cuyos principales negocios consistía, precisamente, en la reventa de bienes que llegaban a la capital. Es posible que los representantes del cuerpo de minería también obtuvieran importantes conce-

9 Entre 1780 y 1783 se despacharon a La Habana cerca de 12 millones de pesos de la renta de tabacos, mientras que en las cuentas de la Tesorería General de Madrid no se registraron los fondos líquidos que se recibían del monopolio de tabaco de Nueva España. Grafenstein, 1968, pp. 148-149; Marichal, 1999, pp. 102-103; TORRES SÁNCHEZ, 2013, pp. 276-280.

10 Sobre el primer "donativo universal" requerido por Felipe $\mathrm{V}$ y los empréstitos que otorgó el Consulado durante que Guerra de Sucesión véase VAlle PaVón, 2004. Sobre otros empréstitos realizados durante el siglo XVIII, VAlLe Pavón, 1997.

11 Donativos que hicieron Tribunales del consulado y minería a los príncipes nuestros señores. AGN, AHH, 338-2.

12 Bando del 20 de octubre de 1780. AGN, Bandos 11, 75, fs. 217-219. Fonseca y Urrutia, Historia, t. II, 1849 , pp. $72,73$. 
siones en compensación por el donativo demandado por el Ministro José de Gálvez, a quien debían su reciente constitución en un cuerpo formal y la erección su tribunal.

En febrero de 1780, el monarca mandó al virrey acopiar en el puerto de Veracruz "los víveres necesarios para la subsistencia de una escuadra de 12 navíos de línea y un cuerpo de 8,000 hombres de tropa, además de un Regimiento para la guarnición de La Habana y que junte cuantos caudales regule necesarios, sin reservar los depósitos, ni el recurrir a los suplementos de particulares ricos, cabildos y comunidades eclesiásticas" ${ }^{13}$. En julio, poco después de recibir dicha real orden, Mayorga mandó a Joseph Manguino, Superintendente de la Real Casa de Moneda y del Consejo de Hacienda, que constituyera un depósito general de caudales con los fondos que resguardaban los tribunales y juzgados seculares y eclesiásticos de los asuntos judiciales pendientes. A pesar de que el arzobispo de México, Alonso Núñez de Haro y Peralta, se resistió a que los juzgados de su competencia entregaran los fondos que custodiaban, en octubre el depósito de la Ceca contaba con poco más de 1,311,000 pesos. Estos fondos procedían de la Real Audiencia, del Corregidor de la ciudad de México, del Intendente de Ejército Subdelegado y Superintendente general de la real Hacienda, del juez conservador del Estado y marquesado del Valle, así como de otros jueces y tribunales seculares. En febrero de 1781, Carlos III aprobó la erección de dicha caja ${ }^{14}$.

Ante la apremiante necesidad de recursos líquidos para sostener el conflicto bélico, el rey aumentó la contribución fiscal en las posesiones de Indias mediante la imposición de un "donativo universal", que gravaba a toda la población con excepción de los esclavos ${ }^{15}$. En agosto de 1780, Carlos III requirió "sólo un peso de todos los hombres libres, así indios, como de otras castas que componen el pueblo, y dos pesos de los españoles y nobles", dinero que se destinaría a proteger los dominios americanos de la "codicia" de la "nación inglesa", destacando que éstos no habían sido gravados como los de España ${ }^{16}$. En el Reglamento para la recaudación del donativo, que se publicó en Nueva España en marzo de 1781, el virrey manifestó su expectativa de que los nobles, hacendados, labradores, mineros, y otros sujetos acaudalados "se señalarán en ofrecer y dar voluntariamente a S. M. lo que más les dicte su amor". Y para asegurar las mayores aportaciones del comercio de México, comisionó al Tribunal del Consulado para recoger las contribuciones "de los comerciantes, tratantes con almacenes, tiendas, caxoncillos [sic], tiendas mestizas, puestos de ropa nueva y vieja, almonederos [sic], y demás negociantes por las calles, y corredores de todas clases de esta capital, y subalternos de su tribunal" 17 .

A los pocos días de que se hubiera solicitado el donativo, el Consulado contribuyó con 26,904 pesos $^{18}$, mientras que algunos de sus miembros más destacados se distinguieron al otorgar dádivas cuantiosas. Uno de los mayores donativos provino del conde de Rábago, quien, poco después de que se había dado a conocer en la ciudad de México

13 Real Orden del 24 de febrero de 1780, citada en Real Díaz y Heredia, 1968, p. 145, nota 10.

14 AGN, Casa de Moneda, 14, fs. 3-40v.

15 Real Díaz y Heredia, 1968, pp. 28-63, 97.

16 Real Cédula del 17 de agosto de 1780. AGN, Bandos, 11, 69, fs. 191-194.

17 Bando del 16 de marzo de 1781. AGN, Bandos 11, 93-95, fs. 286-290.

18 Razón, aunque simple, verdadera, de la franquía de dinero del Consulado de México, AGN, AHH, 64036; Consulados vol. 12-4. 
la noticia del conflicto, había ofrecido al virrey mil corceles para las fuerzas de caballería, pero como sólo se requirieron setenta, donó 10,000 pesos en efectivo. Las aportaciones de Rábago sólo pueden compararse con las de dos de los más ricos mineros, el conde de Regla que donó cerca de 29,000 pesos en trigo y el Conde de la Valenciana que otorgó 25,000 pesos. Entre los mercaderes más acaudalados se distinguieron Pedro Alonso de Alles, quien contribuyó con 4,000 pesos, más 2,000 pesos por cada año de durara la guerra; Servando Gómez de la Cortina que donó 2,000 pesos y Pedro de Vértiz que aportó 1,200 pesos e importantes cantidades de trigo. Estos donativos eran muy considerables y similares a los que efectuaron nobles enriquecidos como el marqués de San Juan de Rayas, la condesa de San Matero de Valparaíso y el marqués del Apartado, cada uno de los cuales cedió 2,000 pesos ${ }^{19}$.

El gobierno de Carlos III había previsto que el donativo se recaudara en un periodo de cuatro meses. Sin embargo, luego de que se recibieron las aportaciones de la capital del virreinato y las poblaciones aledañas, la recaudación fue lenta y complicada, en razón del dilatado tamaño del reino y de que muchas haciendas y comunidades se encontraban en lugares remotos. La recolección del donativo concluyó en noviembre de 1784 . Se ha calculado que el erario virreinal percibió poco más de 843,000 pesos por dicho concepto $^{20}$, sin embargo, creemos que la suma pudo haber sido mayor, ya que localizamos donativos de mercaderes consulares que no fueron contabilizados ${ }^{21}$.

Prácticamente cada año de guerra, el Consulado de México respondió al requerimiento de donativos para las urgencias de la familia real. En respuesta a una real orden de diciembre de 1782 entregó una nueva dádiva por 50,000 pesos, que se cargó al fondo de "sobras de alcabalas" de la corporación ${ }^{22}$. Es muy probable que el Tribunal de Minería también otorgara un donativo por 50,000 pesos, en diciembre de 1782, dado que José de Gálvez solía requerir el apoyo financiero de ambas corporaciones, y que el Tribunal de Minería procedía "siguiendo el ejemplar del real Tribunal del Consulado de Comercio, sobre cuya pauta se ha erigido en Cuerpo formal y autorizado el de nuestra Minería" 23 . En julio de 1783, nuevamente por orden del Ministro José de Gálvez, los Tribunales del Consulado y de Minería otorgaron otra dádiva por 50,000 pesos, cada uno, cuyo total equivalía a un millón de reales de vellón, que los Cinco Gremios Mayores de Madrid habían adelantado para las urgencias de la princesa María Luisa. En septiembre se remitieron los 100,000 pesos a Veracruz para embarcarse a Cádiz, consignados a la Diputación de los Cinco Gremios Mayores ${ }^{24}$. Hasta donde sabemos, los Tribunales del consulado y de minería otorgaron tres donativos por doscientos mil pesos cada uno, más su contribución al donativo Universal.

19 Correspondencia entre Mayorga y Cossío, México, 13 y 14 de febrero de 1782. AGN, Consulados, 306-7. Contribuciones de Alonso de Alles, AGN, Indiferente virreinal, 4787- 50. De Rábago a Gálvez, 12 de diciembre de 1782. AGI, México, 2503.

20 Marichal, 1999, pp. 105-111.

21 AGN, Bandos, 13-22 y 55.

22 Cargos hechos al fondo de sobras de alcabalas, 1782. AGN, AHH, 129-11. Acerca de la constitución y el manejo del fondo de sobras de alcabalas. VALLE PAVÓN, 2007, pp. 1001-1007.

23 Ramírez, 1890, pp. 39-40.

24 Donativos que hicieron Tribunales del consulado y minería a los príncipes nuestros señores. AGN, AHH, 338-2. 
Aun cuando Carlos III hizo grandes esfuerzos por evitar el endeudamiento ${ }^{25}$, la escasez de circulante que se padecía en la Península, como consecuencia de los crecientes gastos bélicos y del bloqueo del Atlántico por parte de los ingleses, condujo al gobierno a crear un nuevo tipo de deuda pública al disponer de los depósitos que resguardaban los cuerpos judiciales y eclesiásticos mediante el pago de réditos. Por real decreto del 15 de marzo de 1780 se mandó "que todos los caudales existentes en depósitos públicos o privados con destino a imponerse a favor de vínculos, mayorazgos, patronatos, capellanías, obras pías, y cualesquiera otras clases de fundaciones, se tomen a censo redimible de cuenta de mi real Hacienda", al 4\% de interés. A mediados de agosto, el monarca hizo extensiva la contratación de la nueva deuda a los territorios americanos, en donde fue garantizada con la hipoteca de los productos de las rentas del tabaco y alcabalas $^{26}$. Marichal planteó que el virrey pospuso el recurso de tomar dinero prestado porque disponía de otros recursos, como los excedentes de los ramos que se enviaban a España ${ }^{27}$. Sin embargo, en octubre de 1780 y en marzo de 1781, Mayorga informó al ministro de Indias que se había valido de todos los medios para convencer a los interesados en los capitales de obras pías, capellanías y comunidades de Indios, que los colocaran a réditos en la Real Hacienda por "las ventajas que lograrían con la seguridad de las hipotecas de las mencionadas rentas", pero no había logrado convencerlos ${ }^{28}$.

\section{SUPLEMENTOS GRATUITOS DE LOS MERCADERES DE MÉXICO}

Al inicio de 1782, el virrey Martín de Mayorga vio agotarse los recursos ordinarios del erario novohispano, mientras que el donativo universal se colectaba con extrema lentitud. En febrero, se reunió con Pedro Antonio de Cossío, Intendente del Ejército y Superintendente de la real Hacienda, a quien informó que, desde el rompimiento de las hostilidades, había remitido a La Habana 16,730,000 pesos y considerables partidas de víveres. Le planteó que se iba a emprender una nueva campaña, que esperaban definiría la conclusión del conflicto, por lo que requería con urgencia otra crecida suma de dinero y víveres, sin que ello implicara alguna carga para el erario ${ }^{29}$. Cossío, quien formaba parte de una familia de comerciantes cántabros establecidos en el puerto de Veracruz desde principios del siglo XVIII, había sido administrador de las rentas reales y director de la Aduana del puerto y, poco después del inicio de la guerra, se había hecho cargo del abasto de las enormes cantidades de harina y otras despensas para alimentar a las fuerzas armadas estacionadas en La Habana ${ }^{30}$. Aprovechando el conocimiento que tenía Pedro Antonio de los "vecinos comerciantes de esta capital, sus posibilidades y amor al rey", Mayorga le pidió que los convocara para solicitarles suplementos, como

\footnotetext{
25 Torres SÁnchez, 2013, pp. 282-285, 306.

26 Real Cédula que manda extender a los Dominios de Indias la imposición de capitales de los Depósitos que hay en ellos, sobre las Rentas de Tabaco o Alcabalas. AGN, Bandos, vol. II, exp. 68 y 69.

27 Marichal, 1999, pp. 102-104.

28 Se hace referencias a las misivas de Mayorga en la carta del conde de Revillagigedo a Diego Gardoqui, México, marzo 31 de 1794. AGI, México, 2519.

29 De Mayorga a Cosío, México, febrero 13 de 1782. AGN, Consulados, 306-7.

30 Real Díaz y Heredia, 1968, t. II, pp. 121-123.
} 
se llamaba a los préstamos a corto plazo que no generaban intereses, los cuales reembolsaría en cuanto lo requirieran, dado que el erario «se halla en la grande pujanza que jamás se había visto, y se deduce de los cuantiosos gastos hechos hasta ahora». El virrey manifestó que los mercaderes no tendrían inconveniente en contribuir con sus caudales porque el bloqueo del Atlántico había suspendido el tráfico con la Metrópoli ${ }^{31}$. Sin embargo, durante los años del conflicto Veracruz fue abastecido en exceso, porque a las remesas que procedían de la Península, se sumaban las de los navíos de "naciones" neutrales, así como el enorme contrabando que realizaban los angloamericanos y los franceses. Mientras que, por Acapulco se recibían bienes asiáticos procedentes de Filipinas y se comerciaba con otras posesiones hispanas del Pacífico.

Pedro Antonio de Cossío convocó a su residencia a cerca de cien miembros del comercio de México para plantearles la demanda del virrey. La mayoría de los asistentes eran miembros del Consulado dedicados a la contratación de mercancías del exterior y de la tierra, giro que dominaban gracias a la concentración de la plata, que era el principal medio de pago internacional. Poco más de la mitad de los convocados accedieron a aportar suplementos y otros manifestaron la imposibilidad de hacerlo porque tenían empleado su dinero en géneros, o lo habían otorgado fiado. Al término de la junta, el prior del Consulado planteó a Cossío que se harían cargo de colectar las aportaciones de los miembros del cuerpo mercantil y el intendente le manifestó la esperanza que tenía el virrey de reunir millón y medio de pesos. Finalmente, se recibieron suplementos de cincuenta y cinco comerciantes, los cuales sumaron poco más de 1,520,000 pesos, treinta y tres contribuyentes eran miembros del Consulado que suplieron 1,062,000 pesos; en cada caso se establecieron diferentes plazos de restitución ${ }^{32}$. Sin lugar a duda, dichos sujetos respondieron a la demanda del virrey por lealtad a la corona y para limitar el avance de los ingleses en Hispanoamérica; no obstante, también tuvieron motivos de carácter económico, social y político. A continuación se analizan diversas causas que pudieron haber influido en la generosidad de los mayores contribuyentes.

Entre los principales contribuyentes de los préstamos gratuitos se encontraban mercaderes hacendados dedicados a la producción agropecuaria y tratantes de ganado en gran escala que abastecían a la ciudad de México $^{33}$. Al parecer, el vínculo que unía a dichos comerciantes con Pedro Antonio de Cossío era su participación en el abasto de las enormes cantidades de trigo, harina, carne salada, cebo, tocino y otros alimentos requeridos por las fuerzas armadas concentradas en La Habana ${ }^{34}$. La necesidad de alimentar a más de ocho mil soldados había determinado que se adquiriera trigo en regiones alejadas de Veracruz y de la ciudad de México, como Celaya y otras zonas del Bajío. Es muy probable que quienes otorgaron dichos suplementos lo hayan hecho para garantizar que el gobierno virreinal continuara comprándoles los mencionados víveres. Entre los casos más destacados se encuentran el del conde de Rábago, propietario de

\footnotetext{
31 De Mayorga a Cossío, México, febrero 13 de 1782. AGN, Consulados, 306-7.

32 Suplementos del comercio de México. AGN, Consulados, 306-7; AHH, 640-49.

33 De Mayorga a Cossío, México, febrero 13 y 14 de 1782. AGN, Consulados, 306-7. Préstamos del comercio de México, 1782. AGI, México, 2503.

34 Sobre el abasto de harinas a los almacenes de La Habana durante la guerra, véase GrafEnstein, 1997, pp 150-160.
} 
varias haciendas ${ }^{35}$, que suplió 102,000 pesos, además de 98,000 pesos en trigo y plata en pasta. El cónsul Antonio de Bassoco, que prestó 100,000 pesos por seis meses, era uno de los mayores tratantes de ganado del virreinato, mientras que su primo y cuñado, el marqués de Castañiza, y el hermano de éste, poseían cinco haciendas en las cercanías de la ciudad de México y tres más en el valle de Cuernavaca, dedicadas a la producción de granos y ganado ${ }^{36}$. Pedro Alonso de Alles, quién otorgó 100,000 pesos $^{37}$, era otro importante tratante de ganado, la mayor parte del cual procedía de los latifundios del marqués de Altamira y del Conde de Sierra Gorda, cuyas propiedades estaban bajo su administración ${ }^{38}$. Un último ejemplo es el de Joaquín Dongo, que contribuyó con 20,000 pesos, quien se dedicaba a la cría de cerdos y la fabricación de sus derivados y, cuando menos, desde 1768 había estado involucrado en la provisión de víveres para la real armada y presidios de Barlovento ${ }^{39}$.

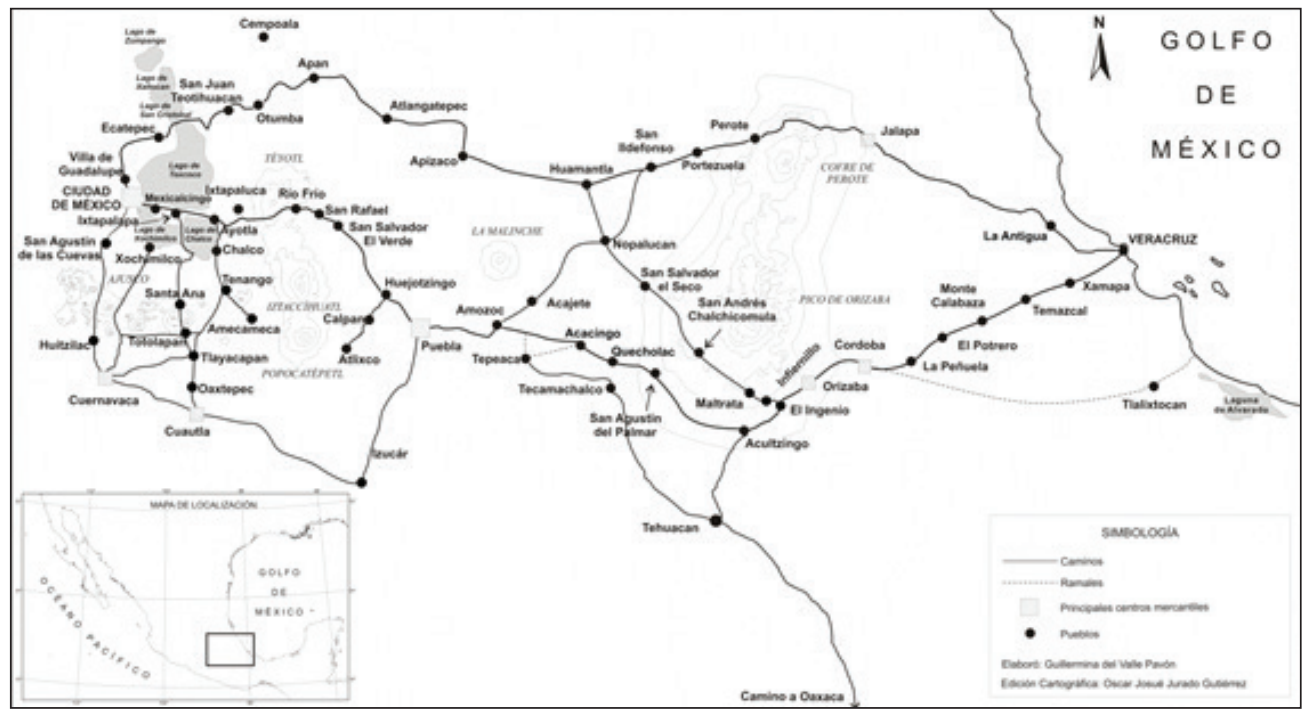

Fig. 1. Caminos México-Veracruz y sus conexiones a finales del siglo XVIII.

Otra de las principales razones por las que acaudalados almaceneros de México otorgaron a la corona cuantiosos suplementos para contribuir al financiamiento de la guerra, fue por su interés en influir en las autoridades reales para que dieran licencia al Consulado para reconstruir el camino que articulaba la capital con el puerto de Veracruz, por las rutas que favorecían sus negocios. Desde el inicio de la guerra el

35 De Rábago a Gálvez, México, diciembre 16 de 1782. AGN, AHH, 640-49. Testamento de Francisco Antonio de Rábago, marzo 1 de 1785. AGNCM, not. Esteban José Pavía, v. 3445. BorChart, 1984, pp. 159, 160, 271, 272.

36 Valle Pavón, 2010.

37 De Mayorga a Cossío, México, febrero 13 y 14 de 1782. AGN, Consulados, 306-7; AGN, Indiferente virreinal, 4787-50.

38 Valle PaVÓn, 2012, pp. 80-81.

39 Borchart, 1984, pp. 177, 270. AGN, AHH, 1196, f. 229r. Agradezco a Johanna von Grafenstein haberme facilitado esta referencia. 
mal estado de los caminos había dificultado la remisión de los víveres y suministros requeridos en La Habana, por lo que se había visto la necesidad de transformar en vía carretera una de las rutas que enlazaban a la ciudad de México con el puerto. En el mapa Caminos México-Veracruz y sus conexiones a finales del siglo XVIII puede verse cómo ambos núcleos mercantiles se conectaban a través de diversas vías. Gran parte de los comerciantes que contribuyeron con el suplemento estaban interesados en que se reconstruyera el camino que salía por el sureste de la capital, rumbo a la ciudad Puebla, de donde se dirigía al puerto por la parte meridional del macizo montañoso conocido como Pico de Orizaba. Este camino tenía, entre otras ventajas, la de enlazar con las vías que comunicaban con el sur y sureste del virreinato. De modo que su reconstrucción haría más ágil y barato el transporte a Veracruz del trigo, la harina y otros alimentos que se producían en el valle de México, Michoacán y el Bajío, así como del algodón, las mantas, la grana, el añil y el cacao que se producían en la Costa de Sotavento de Veracruz, Oaxaca, Tabasco, Soconusco y Guatemala ${ }^{40}$.

La elección de la ruta por reconstruir, había adquirido gran relevancia para los mercaderes consulares porque, a raíz de la apertura comercial, la frecuente llegada de navíos les había hecho perder el control sobre la redistribución de los bienes europeos en el virreinato. En consecuencia, habían canalizado parte del dinero que tenían invertido en el tráfico atlántico a la producción, financiamiento y comercialización de los bienes de la agricultura especializada. Además, los precios del algodón y los tintes se habían incrementado como consecuencia de la creciente demanda de la industria textil, doméstica y europea, mientras que en el Reglamento de aranceles reales para el comercio libre de España a Indias, de 1778, dichos productos habían quedado exentos del pago de derechos a su entrada a la Península ${ }^{41}$. Por otra parte, en caso de que se implantara el mencionado Reglamento en Nueva España, era muy posible que se establecieran nuevos $\operatorname{consulados}^{42}$, cuya jurisdicción territorial se establecería a costa de la que tenía el de México, lo que obligaría a sus miembros a concentrar sus negocios en la jurisdicción de la Audiencia de México.

Entre los almaceneros que otorgaron elevados suplementos también se encontraban los que se dedicaban a la contratación de cacao de Guayaquil, muy probablemente con la inteción de que el virrey les otorgara licencias para introducir grandes cantidades del grano por por Acapulco ${ }^{43}$. Luego de que el comercio del fruto guayaquileño había tenido un notable incremento a raíz de la apertura limitada del tráfico por el Pacífico, en 1774, las quejas del intendente del Caracas porque se había reducido la demanda y el precio del cacao caraqueño, habían dado lugar a que, en 1777, el monarca limitara el ingreso de cacao de Guayaquil por Acapulco a 10 mil fanegas anuales. En agosto de 1779, ante el bloqueo del tráfico Atlántico ocasionado por la guerra, la Audiencia gobernadora había autorizado la introducción del cacao de Guayaquil por Acapulco "sin limitación alguna". En esta decisión había tenido un papel relevante el oidor Francisco Xavier Gamboa, que era aliado de los mercaderes consulares. Casi un año después, el monarca, nuevamente presionado por el intendente de Caracas, había

\footnotetext{
40 Valle PaVón, 2007b, pp. 438-444.

41 Borchart, 1984 , pp. 66,118 , nota 3.

42 Reglamento, 1979, art. 53, pp. 24-25.

43 Valle Pavón, 2010, pp. 191-194.
} 
mandado restablecer el límite a la entrada del fruto guayaquileño por Acapulco, por lo que se habían negado a varios comerciantes los permisos para desembarcar el cacao. Es posible que los suplementos de los mercaderes lograran que privara el fallo de la Audiencia, lo que mantuvo elevado el comercio del grano de Guayaquil, hecho en el que también influyo las licencias que otorgó Carlos III para contratar dicho producto con el propósito de allegarse recursos extraordinarios ${ }^{44}$.

Por otra parte, se ha demostrado cómo la monarquía recurría a la venta de cargos y distinciones durante las coyunturas belicas para hecer frente a los crecientes gastos que se generaban ${ }^{45}$. De modo que algunos mercaderes pudieron haber concedido elevados suplementos para la campaña contra los ingleses con el propósito de conseguir nombramientos, honores o títulos nobiliarios. Servando Gómez de la Cortina había solicitado al soberano un título de Castilla, en atención a su origen ilustre y a los servicios pecuniarios que había prestado, entre los que se destaca el suplemento que había hecho a la Casa de Moneda por 110,000 pesos para facilitar el cambio de la moneda antigua por la de nuevo cuño, de los cuales sólo había cobrado 40,000 pesos, donando el resto para el servicio de la ceca. A este cuantioso servicio había agregado, en 1781 , el donativo por 2,000 pesos, el suplemento gratuito por 50,000 pesos y mil cargas de trigo ${ }^{46}$. Teniendo en cuenta la recomendación del virrey Martín de Mayorga por los generosos servicios que había otorgado, la Cámara de Indias determinó que se le concediera el título de conde de la Cortina, en diciembre del mismo año de $1782^{47}$. Por otra parte, Pedro Alonso de Alles, quien servía a la monarquía como tesorero de la Bula de la Santa Cruzada desde 1769, en 1784 fue designado ministro honorario del real tribunal y audiencia de cuentas de México, muy probablemente en reconocimiento a los donativos y suplementos que había otorgado ${ }^{48}$.

Vale la pena examinar el caso del conde Domingo Antonio de Rábago, cuyo anhelo por satisfacer las necesidades financieras de la corona se explica, principalmente, por su empeño en hacerse merecedor del favor del monarca, el Ministro de Indias y el virrey. El conde había sido marginado políticamente por el virrey Antonio María de Bucareli, a raíz del escándalo que había suscitado en 1776, cuando había denunciado a los ex priores del Consulado por haber acumulado de manera ilícita, un fondo de poco más de un millón de pesos con las "sobras" de los productos de la renta de alcabalas, cuya administración había estado a cargo del cuerpo mercantil de 1694 a 1753. Dicho fondo era manejado en secreto por el prior y sus antecesores, en beneficio de sus intereses y los de sus allegados. Domingo Antonio había hecho tal acusación debido a su inconformidad porque en las elecciones consulares celebradas en 1776, su hermano, el capitán Francisco Antonio de Rábago, siendo el candidato de la facción de los montañeses, a la que correspondía nombrar al cónsul, no había sido electo por motivos fraudulentos. En diciembre de 1782, luego de que el conde había otorgado al virrey cuantiosos donativos en dinero, trigo y caballos, así como el mayor suplemento para el sostenimiento de la guerra, se dirigió al ministro de Indias, José de Gálvez, para suplicarle que declarara que

\footnotetext{
44 Ibídem, pp. 194-200.

45 Andújar Castillo, 2004, pp. 30-33.

46 De Cossío a Mayorga, México, febrero 14 de 1782. AGN, Consulados, 306-7.

47 La Cámara de Indias 1782. AGI, Indiferente, 1609-14.

48 AGN, Tribunal de Cuentas (112), v. 42-11.
} 
él y su hermano no habían sido descalificados para ocupar los ministerios del Consulado. La petición del conde de Rábago se explica porque "sus contrarios" habían persuadido al virrey Bucareli de que el soberano había inhabilitado al conde y a su hermano para ocupar cualquier empleo, por lo que en 1779, cuando los montañeses habían vuelto a postular al capitán Francisco Antonio para el oficio de cónsul, Bucareli había declarado en público que "si acaso salía electo cónsul el referido capitán, su Excelencia lo embarazaría, puesto que el Rey lo tenía inhabilitado". El conde se quejaba de que este suceso lo había deshonrado y había fortalecido a sus enemigos ${ }^{49}$.

Servando y José Gómez de la Cortina habían brindado su apoyo al conde de Rábago cuando había revelado la existencia del fondo de alcabalas, por lo que Bucareli también los había declarado incapacitados para desempeñar los oficios del Consulado. Es muy posible que Servando hubiera efectuado los cuantiosos servicios financieros que mencionamos con el propósito de que las autoridades disculparan su participación en el escándalo que habían ocasionado al ventilar los malos manejos y los conflictos internos del Consulado, que era considerado uno de los pilares de la monarquía. Todo indica que tuvieron éxito los esfuerzos del conde de Rábago y Servando Gómez de la Cortina por reparar los males ocasionados, ya que Francisco Antonio de Rábago fue designado para ocupar el oficio de cónsul en el bienio 1784-1785, Servando Gómez de la Cortina desempeñó el mismo ministerio en 1787-1788, mientras que Gabriel Gutiérrez de Terán, que era primo de los Gómez de la Cortina y cuyo hermano Damián había formado parte del grupo disidente, fue electo prior para 1785-1786.

En febrero de 1782, el virrey también requirió al Intendente Pedro Antonio de Cossío que solicitara a los agentes de los cargadores de Cádiz que se encontraban en México suplementos para la guerra, con el mismo argumento de que, debido a la parálisis comercial, les era indiferente "tener en sus propias casas este caudal, o en las cajas reales". Mayorga se comprometió a reembolsar el dinero adelantado cuando se restableciera el tráfico por el Atlántico. De los veintinueve tratantes reunidos por el Intendente, veintiuno lamentaron no poder satisfacer la demanda del virrey porque los mercaderes de Cádiz eran los "legítimos dueños" del dinero que tenían de lo vendido y de lo mucho que tenían en "efectos". El virrey además se valió del diputado de la última flota para demandar préstamos sin interés a los factores de España que se encontraban en la villa de Xalapa de la Feria. De los préstamos gratuitos efectuados por los matriculados del comercio de España se colectaron 408,000 pesos. Ocho consignatarios que se encontraban en México aportaron 205,000 pesos, cifra que representó poco más de la mitad del total aportado; mientras que en Xalapa los veintisiete factores a los que se planteó la demanda contribuyeron con 203,000 pesos. ${ }^{50} \mathrm{Al}$ parecer, en retribución por los suplementos otorgados, el virrey autorizó a los encomenderos andaluces a internarse en Nueva España para vender los rezagos de la última flota.

49 De Rábago a Gálvez, México, diciembre 16 de 1782, AGI, México, 2503. Sobre la denuncia del fondo de sobras de alcabalas y sus consecuencias para el Consulado, véase VALLE PAVón, 2007a, pp. 979-982.

50 AGN, Consulados, 306-7. 


\section{INTERMEDIACIÓN FINANCIERA DE LOS TRIBUNALES DEL CONSU- LADO Y DE MINERÍA}

El conflicto bélico en el Caribe continuó consumiendo enormes capitales. En junio de 1782 el erario virreinal carecía de fondos para continuar con las crecidas remesas de caudales a Cuba, por lo que el virrey consultó a los Juzgados del Consulado y de Minería sobre las cantidades que podrían aprontarle "con calidad de reintegro". Los representantes de ambas corporaciones plantearon a Mayorga que carecían de dinero, pero se ofrecieron a operar como intermediarios financieros de la real Hacienda con el propósito de conseguir un millón de pesos a réditos cada uno. Como veremos a continuación, los poderosos cuerpos no procedieron de manera desinteresada, aprovecharon la oportunidad para negociar con el virrey y las autoridades de la metrópoli demandas importantes.

El Consulado propuso solicitar el millón de pesos a premio del 5\%, lo que suponía pagar 50,000 pesos anuales por concepto de réditos, suma que podría obtenerse mediante un incremento del cuatro al millar extraordinario al derecho de avería consular, que gravaba con seis al millar las mercancías que entraban por mar al virreinato. El virrey autorizó la contratación del empréstito y el aumento de la avería ${ }^{51}$. Los representantes de los mercaderes plantearon al ministro de Indias que la corporación demostraba su lealtad al rey tanto al obtener los caudales requeridos y otorgar las escrituras correspondientes, como al erogar los fondos necesarios para el pago de los intereses, porque el recargo del derecho de avería sería satisfecho principalmente por sus miembros ${ }^{52}$. No obstante, la tasa extraordinaria de avería podía ser transferida a los consumidores, de manera parcial o total, mediante el aumento de los precios de las mercancías. Además, los productos de la avería adicional pudieron haber sido superiores a los 50,000 pesos requeridos, dado que en los años siguientes se incrementó el ingreso de mercancías al virreinato como consecuencia de la apertura comercial.

Presumimos que una de las principales causas por las que el cuerpo mercantil aceptó reunir el préstamo millonario fue su interés en influir en las autoridades reales para evitar que se introdujera en Nueva España el Reglamento de aranceles reales para el comercio libre de España a Indias de 1778. El consulado también pudo haber dado su apoyo financiero con el fin de conseguir que se estableciera el comercio libre de harinas para poder abastecer a La Habana, lo que implicaba enfrentar la competencia de angloamericanos que operaban con plena libertad y contaban con transportes marítimos más rápidos y baratos ${ }^{53}$. El 21 de agosto de 1782, unos días después de que el Consulado entregara la suma requerida, se implantó en el virreinato la libertad para comerciar harina, por decisión de la Junta de real Hacienda que convocó el virrey, luego de que el fiscal de real Hacienda, Ramón Posada, criticara el "monopolio" que había organizado Pedro Antonio de Cossío para suministrar harina a $\mathrm{Cuba}^{54}$.

\footnotetext{
51 Expedientes sobre el empréstito del Consulado por un millón de pesos. AGN, AHH, 640-49; 683-34 y 1869-18.

52 Del Consulado a Gálvez, México, diciembre 6 de 1782. AGI, México, 2504.

53 En 1781 arribaron a La Habana 126 navíos mercantes norteamericanos y en 1783, luego de que se abrió la línea marítima entre La Habana y Filadelfia, anclaron 183 barcos en dicho puerto. BötTCHER, 2011, p. 223.

54 Real Díaz y Heredia, 1968, pp. 125-128.
} 
Asimismo es probable que en la negociación para la recolección del préstamo el Consulado hubiera considerado la reconstrucción del camino México-Veracruz por la ruta que salía por el sureste del Valle de México, continuaba por la ciudad de Puebla y la villa de Orizaba para llegar al puerto. Como vimos, uno de los principales interesados en dicho proyecto era Antonio de Bassoco, cónsul del Tribunal Mercantil, que buscaba favorecer el transporte de los bienes que se producían en las tierras de que poseían los Castañiza en la jurisdicción de Coatepec. Unos meses después el virrey recibió la orden de Carlos III de emprender mayor actividad en la composición de caminos, en respuesta a las preocupaciones que había manifestado ${ }^{55}$. El capitán e ingeniero Diego de Panes, que estaba vinculado con un sector de mercaderes del Consulado, se ofreció para realizar el reconocimiento de los caminos que conducían a Veracruz, para lo cual fue recomendado con el virrey por el fiscal Ramón Posada. En febrero de 1783, Mayorga comisionó al ingeniero Panes para examinar el estado de las vías que articulaban a la capital con el puerto y proponer los tramos más favorables para transformarlos en carreteros ${ }^{56}$.

Poco después de que el Tribunal Mercantil empezó a solicitar los depósitos a réditos recibió ofertas superiores a 1,600,000 pesos, por lo que tuvo que seleccionar a los deponentes ${ }^{57}$. La gran oferta de caudales puede explicarse, por una parte, por las redes financieras que tenían los representantes del Consulado y porque dicha inversión resultaba atractiva por la confianza que generaba el cuerpo en que se agrupaban los hombres más acaudalados del virreinato. Y por otra, por razones de carácter estructural, ya que, desde fines de la década de 1760, la economía novohispana había recibido un notable impulso como consecuencia del crecimiento de la población, el auge de la producción de argentífera y el dinamismo que presentaba el comercio Pacífico luego de su apertura en 1774. Como parte de la reactivación económica, la disposición de fondos crediticios se había expandido notablemente, fenómeno que se evidencia por el incremento que presentaban las fundaciones piadosas y la creación de congregaciones que administraban los fondos píos $^{58}$. Sobre este fenómeno el real fisco de la Inquisición declaró «Hay cantidades de pesos de consideración, detenidas muchos años hace [...]. Porque la abundancia de pesos, originada de la bonanza de minas, y otras causas, han hecho experimentar cada día muchas redenciones de gravámenes [...]. Y porque comunidades, tribunales y archicofradías tienen dinero de sobra para dar a cuantos necesitados llegan a pedir» ${ }^{59}$.

Del millón de pesos que recibió el Tribunal Mercantil, 449,000 pesos fueron depositados por ocho miembros del cuerpo mercantil; 353,000 pesos pertenecían a ocho corporaciones eclesiásticas y a una capellanía; mientras que los 198,000 pesos restantes fueron colocados por siete personas que querían contribuir con la causa bélica y hacer redituar su dinero sin correr riesgos. Entre los miembros del consulado se destaca Manuel García Herreros, quien colocó 230,000 pesos, cantidad exorbitante con la que se podía adquirir una de las mejores haciendas de la época. Este, al igual que Antonio de

\footnotetext{
55 Real orden de agosto 20 de 1782. AGN, Fomento caminos, 3.

56 Panes y Abellán, 1783, fs. 50-51.

57 Del Consulado a Gardoqui, México, abril 28 de 1794. AGI, México, 2506.

58 Valle PaVÓn, 2014, pp. 507-538.

59 Citado en Wobeser, 1994, p. 85.
} 
Bassoco y la mayor parte de los almaceneros que brindaron apoyo financiero a la corona se oponía a la apertura comercial ${ }^{60}$. Con excepción de un mercader, el resto de los que confiaron caudales al tribunal del Consulado habían otorgado suplementos gratuitos en febrero. Además, tres de ellos eran personas mayores poseedoras de grandes caudales, que solían limitar sus transacciones comerciales y colocar a réditos buena parte de su dinero. Como ejemplo tenemos a José de Zevallos, quien, en la década de 1770, había prestado a corto plazo montos que fluctuaban entre 20,000 y 50,000 pesos, cuando menos, a cuatro miembros del cuerpo mercantil ${ }^{61}$.

El segundo grupo de deponentes estaba constituido por corporaciones religiosas que solían invertir a interés gran parte de los fondos que poseían, así como los que pertenecían a las fundaciones piadosas y capellanías que estaban bajo su administración ${ }^{62}$. Estos cuerpos buscaban afianzar sus caudales al máximo, por los riesgos que presentaba el otorgamiento de crédito en Nueva España. Cuando el capital se garantizaba con la hipoteca de una propiedad raíz, ésta podía estar recargada con gravámenes, circunstancia que ponía llevar a enfrentar un concurso de acreedores, en los que, generalmente, sólo eran cubiertos los prestatarios más antiguos. Además, los precios de los inmuebles en la ciudad de México tendían a reducirse debido al incremento que entonces presentaba la oferta de bienes raíces. Por otra parte, cuando los créditos eran avalados por fiadores, se corría el riesgo de que quebraran, lo que era frecuente en el virreinato ${ }^{63}$. El Santo Oficio de la Inquisición depositó 200,000 pesos, por la seguridad que brindaba el cuerpo mercantil. La Cofradía de Nuestra Señora de Aránzazu, en la que se agrupaban los mercaderes de origen vasco, depositó 64,000 pesos, muy probablemente por influjo de Antonio de Bassoco, que había sido rector en 1780-178164. El Oratorio de San Felipe Neri, del que Bassoco era protector ${ }^{65}$, coloco 7,000 pesos y el Colegio de Indias de Nuestra Señora de Guadalupe, que había sido fundado por el doctor Juan Francisco de Castañiza, que era su confesor y principal benefactor entregó 1,000 pesos $^{66}$. También se recibieron caudales de cuatro conventos de religiosas y los fondos de una capellanía establecida por el conde de Medina y Torres, que era presbítero de la Catedral metropolitana. Por último, se encontraban nueve personas que depositaron dinero en el tribunal mercantil con el propósito de obtener una renta segura y el reconocimiento real. Entre estos se destaca Francisco Antonio Pérez de Soñanes, originario de Cantabria, quien se había enriquecido en la minería y se esforzaba por conseguir un título nobiliario ${ }^{67}$.

Para el virrey resultó más difícil obtener el empréstito del Tribunal de Minería. Poco antes de plantear su demanda, los mineros habían protestado por el anuncio de que se

\footnotetext{
60 El descontento que generó la introducción del Reglamento de libre comercio en Nueva España, en 1789, dio lugar a que el virrey Revillagigedo consultaría a doce prominentes miembros del consulado sobre la situación del comercio en el virreinato. Entre los consultados se encontraban García Herreros y Bassoco, quienes se manifestarían en contra del nuevo régimen. AGN, Consulados, v. 123.

61 Borchart, 1984, pp. 67, 69, 90.

62 Wobeser, 1994, pp. 11-19, 55-63, 93-101, 115-125; Valle Pavón, 2014, pp. 508-531.

63 WoBeser, 1994, pp. 81-85.

64 Sobre el papel financiero de la Cofradía de Aránzazu, Valle Pavón, 2014, pp. 518-520, 525-529.

65 Testamento de Antonio de Bassoco, México, febrero 4 de 1809. AGNCM, Juan Manuel Pozo, notario núm. 522.

66 Muriel, 1946, pp. 461, 463-465.

67 Título de conde de la Contramina. AGI, Indiferente 1609, 113.
} 
elevaría el precio del quintal de azogue debido al aumento en el costo del transporte ocasionado por el bloqueo en el Atlántico. El Tribunal de minería aceptó hacerse cargo de recabar el millón de pesos, a condición de que no se aumentara el precio del mercurio, y propuso pagar los intereses con la imposición de un derecho extraordinario de diez granos sobre la acuñación de cada marco de plata. La oferta fue aprobada por Mayorga, pero ocasionó un debate entre los mineros y los aviadores porque el nuevo gravamen sobre la amonedación se agregaría a los ocho granos que ya se cobraban para el "fondo dotal" del cuerpo minero, que debía destinarse al fomento de la minería. Un grupo propuso que el servicio del préstamo se pagara con el mismo "fondo dotal", medida que era coherente con la política borbónica que buscaba reducir las cargas sobre la actividad minera. Sin embargo, el tribunal minero se negó a recargar su "fondo dotal", cuyos productos se destinaban a pagar el servicio de un préstamo por 300,000 pesos, otorgado en 1776 para la construcción del muelle y los astilleros de Coatzacoalcos, y el donativo por 100,000 pesos hecho en 1781 para al Príncipe de Asturias. Finalmente sólo se impusieran cuatro granos extraordinarios sobre la amonedación de cada marco de plata para pagar el servicio del empréstito ${ }^{68}$.

El Tribunal de Minería sólo pudo conseguir depósitos por 890,000 pesos, para completar el millón de pesos requerido tuvo que aportar 110,000 pesos de su "fondo dotal" Del dinero negociado por el Tribunal de Minería, 300,000 pesos fueron colocados por miembros de la familia Castañiza-Bassoco. El cónsul moderno del Tribunal Mercantil, Francisco Martínez Cabezón, confió al Tribunal de Minería 200,000 pesos, posiblemente, con la pretensión de influir en las autoridades en contra del comercio libre. Martínez Cabezón tenía intereses en la minería y, unos años después, junto con Antonio de Bassoco, canalizaría parte de sus capitales a la Compañía Minera Bolaños, de la que fue el mayor inversionista y administrador ${ }^{70}$. Otro importante grupo de contribuyentes fueron las corporaciones civiles y eclesiásticas, entre las que se destacó el Santo Oficio de la Inquisición, que colocó 100,000 pesos. También situaron caudales cuerpos vinculados a la administración regia, el Monte Pío de Ministros, la Real Casa de Moneda, las Reales Cajas de la ciudad de México y el Real Hospital General de Indios ${ }^{71}$.

\section{DEPÓSITOS COLOCADOS A RÉDITO EN LA REAL HACIENDA}

A fines de diciembre de 1782 el Intendente de La Habana solicitó al virrey de Nueva España cinco millones de pesos de manera apremiante, luego de que en el transcurso del año había recibido más de doce millones de pesos. Para satisfacer la urgente demanda de caudales, en junta extraordinaria de real Hacienda se resolvió aplicar la real cédula de agosto de 1780, que mandaba establecer una nueva deuda mediante la colocación en el real erario, a censo redimible, los depósitos existentes en los cuerpos judiciales y eclesiásticos. En enero de 1783, el virrey publicó la real orden y el reglamento para crear la nueva deuda, en la que el soberano mandaba destinar a las cajas reales el dinero que

\footnotetext{
68 Howe, 1949, pp. 84-85, 93-97, 118-119, 372, 376-379.

69 Ibídem, pp. 84-85.

70 Constitución de Compañía 1788. AHNCM, Juan Manuel Pozo, notario 522, v. 3487.

71 Howe, 1949, pp. 84, 85.
} 
estuviera "bajo la autoridad de los jueces eclesiásticos", el que tuvieran particulares y comunidades para imponer a réditos, así como los "sobrantes de propios y arbitrios que tengan desembarazados las ciudades, villas, pueblos de españoles e indios, y los que existan en las cajas de censos de éstos". Se argumentaba que las obras pías, los pueblos de indios, las comunidades y los particulares serían beneficiados con el pago de intereses. Asimismo se planteaba que el monarca había extendido a los dominios de Indias el financiamiento de la nueva deuda pública, luego de haber "logrado con general satisfacción poner en valor unos capitales que se hallaban como muertos en los depósitos" 72 , lo que deja ver el carácter desamortizador de esta medida.

Como a fines de 1780 y principios de 1781 había resultado imposible para Mayorga recibir los capitales de obras pías, capellanías y comunidades de Indios, en el bando que emitió apeló a la lealtad de todos los súbditos para que franquearan cuantos caudales tuvieran para imponer a rédito. Y, aun cuando en el Reglamento para la recepción de depósitos en Indias se establecía que se debía pagar el 4\% de interés por los capitales recibidos, se otorgó la tasa del 5\%, que regía en Nueva España. La restitución de los depósitos y el pago de los intereses que generaran fueron garantizados con los productos de la renta de tabaco, que era el ramo del erario virreinal más rentable, después de los ingresos generados por la producción de plata ${ }^{73}$. Mayorga exhortó a los arzobispos, obispos, cabildos eclesiásticos y a los superiores de todas las religiones a que cooperaran para cumplir la voluntad del rey, entregando los capitales que se encontraban a su cargo y mandando a las comunidades religiosas, cofradías y archicofradías de sus respectivas jurisdicciones que entregaran en las cajas reales los capitales destinados a imponerse a réditos ${ }^{74}$.

En marzo de 1783, el arzobispo de México, Alonso Núñez de Haro y Peralta, puso objeciones a dicho mandato y ofreció a Mayorga otros apoyos. Es posible que entonces aprovechara el virrey para dar a conocer al arzobispo la real orden del 17 de agosto de 1782, que mandaba a los tribunales y jueces eclesiásticos del Arzobispado de México que colocaran los caudales que resguardaban en el Depósito la Real Casa de Moneda, como lo venían haciendo los tribunales y juzgados seculares, desde septiembre de 1780. Al parecer, Núñez de Haro y Peralta ya no pudo negarse a entregar a la Ceca los fondos demandados. Meses después el ministro de Indias, José de Gálvez, se dirigió al arzobispo para darle a conocer la Real Orden del 20 de agosto de 1783, referente a la entrega de los caudales que resguardaban los tribunales del Arzobispado en el Depósito General de la Ceca, en la que el monarca hizo saber a Núñez de Haro que la Casa de moneda quedaba "obligada y responsable" a entregar los depósitos recibidos, "siempre que los interesados los necesiten o Vuestra Ilustrísima o sus Jueces lo manden, entendiéndose con el tesorero de dicha Real Casa que nunca puede tener falencia". El reembolso de dichos caudales se efectuó en el último tercio de $1787 .{ }^{75}$

72 Real Cédula de S.M. en que se manda extender a los Dominios de Indias la imposición de capitales de los Depósitos, que hay en ellos, sobre las Rentas del Tabaco, o de Alcabalas establecidas en los mismos Dominios, 17 de agosto de 1780. AGI, México, 4349.

73 Los ingresos brutos del monopolio de tabaco incrementaron de manera espectacular entre 1765 y mediados de la década de 1780. Deans-Smith, 1999, pp. 69-105.

74 Bando de enero 18 de 1783. AGN, Bandos, 12-43.

75 AGN, Casa de Moneda, 14. 
En la misma real orden Carlos III se refirió a la imposición de depósitos y capitales a censo en el Real Erario, y manifestó al Arzobispo que con la paz había cesado la necesidad de dichos recursos y que nunca había sido "Su Real ánimo que se tomaran para su Real Hacienda sin el expreso y voluntario convenio de las partes..."

En su esfuerzo por captar la mayor cantidad posible de caudales para la nueva deuda, Martín de Mayorga solicitó a los representantes del Consulado que convocaran a sus miembros para que franquearan los caudales que pudieran ${ }^{77}$. De acuerdo con un informe de la tesorería general de la renta del tabaco, en la ciudad de México se recibieron 364,530 pesos a censo sobre la Real Hacienda. La mayor parte de los caudales se colocaron entre el 27 de enero y el 11 de abril de 1783. Entre las personas, nuevamente se distinguió el marqués de Castañiza, así como otros miembros de antiguas linajes que también habían colocado dinero a réditos en los Tribunales del Consulado y Minería. Varias hermandades piadosas canalizaron a la tesorería de la ciudad de México los depósitos de los fieles que habían establecido fundaciones piadosas con el propósito de obtener indulgencias, muy probablemente por influencia de los mercaderes que formaban parte de sus mesas de gobierno. Como ejemplo tenemos los cuantiosos depósitos que colocó la Cofradía de Nuestra Señora del Rosario, de cuya mesa formaban parte Francisco Antonio de Rábago y Pedro Alonso de Alles ${ }^{78}$, quienes, como vimos, querían congraciarse con las autoridades reales por diferentes motivos. También se captaron depósitos de conventos, probablemente debido a la influencia de los mercaderes que fungían como sus tesoreros y mayordomos. De las corporaciones civiles se destacan los depósitos del Monte Pío de Ministros y de la Junta Académica de las Tres Artes, que estaba estrechamente vinculado a la Casa de Moneda $^{79}$.

Así, entre 1780 y 1783 Mayorga logró reunir únicamente en la ciudad de México, cuando menos 4,517,000 pesos por concepto de donativos, suplementos, préstamos a réditos y depósitos a censo en la Real Hacienda. La relación de estas contribuciones puede verse en el siguiente cuadro.

\begin{tabular}{|l|r|}
\hline \multicolumn{2}{|c|}{ Contribuciones extraordinarias obtenidas en ciudad de México para la guerra } \\
contra Gran Bretaña, 1780-1783 \\
\hline Donativos del Tribunal del Consulado & 227,000 \\
\hline Donativos del Tribunal de Minería & 200,000 \\
\hline Suplementos de los mercaderes y vecinos de México & $1,520,000$ \\
\hline Suplementos de los consignatarios del comercio de Cádiz & 205,000 \\
\hline Empréstito del Consulado de Mercaderes & $1,000,000$ \\
\hline
\end{tabular}

76 Real orden de agosto 20 de 1783. AGN, Casa de Moneda, 369-21.

77 De Mayorga al Consulado, México, enero 18 de 1783. AGN, AHH, 640-649.

78 VAlle PaVÓN, 2012, pp. 36-41.

79 Estado que manifiesta los réditos que ha satisfecho la tesorería general de la Renta del Tabaco de este Reino de N. E. el año de 1783 por los capitales impuestos en él al cinco por ciento sobre la Real Hacienda en las cajas reales de esta Ciudad, los cuales se redimieron el mismo año». BN, ms. 3021. 


\begin{tabular}{|c|r|}
\hline Empréstito del Tribunal de Minería & $1,000,000$ \\
\hline Depósitos a censo recibidos a cuenta de la renta de Tabaco & 365,000 \\
\hline Total & $4,517,000$ \\
\hline
\end{tabular}

\section{CONCLUSIONES}

Para financiar los gastos de la costosa guerra que se libró contra Gran Bretaña en el Caribe y satisfacer las necesidades de los miembros de la casa real, el Ministro de Indias y el virrey Nueva España obtuvieron recursos extraordinarios principalmente del Consulado de la ciudad de México y sus miembros y, de manera secundaria, del Tribunal de Minería. El otorgamiento de caudales en forma de donativos y préstamos fortaleció al cuerpo mercantil que, en recompensa a sus demostraciones de lealtad al rey, obtuvo prebendas de carácter fiscal y comercial. En consecuencia, los esfuerzos de los reformistas por debilitar al poderoso Consulado de México tuvieron que posponerse, mientras que la política comercial de la corona fue socavada, cuando menos durante el tiempo que duró la contienda bélica.

Con respecto al donativo universal que se impuso en Nueva España en 1780, el Consulado operó como un brazo de la Real Hacienda al recolectar las contribuciones del comercio de México, en esta forma se garantizó que las numerosas personas dedicadas a la contratación en la ciudad capital otorgaran parte de sus bienes para apoyar las campañas militares. El cuerpo mercantil, que tenía el privilegio de aplicar la justicia privativa y representar los intereses de sus miembros, era considerado uno de los pilares de la monarquía y, como tal, debía respaldar a las autoridades reales en situaciones de emergencia, entre las que se destacaban el socorro de las necesidades generadas por las guerras. Por su parte, los miembros más destacados de la Universidad de mercaderes pusieron el ejemplo al distinguirse por los cuantiosos donativos que otorgaron, en algunos casos comparables con los que dieron los nobles acaudalados y los más ricos mineros del virreinato.

El predominio de los valores aristocráticos en Nueva España estimuló a ciertos mercaderes a otorgar cuantiosos préstamos gratuitos, los cuales solían ser recompensados con el otorgamiento de títulos nobiliarios y otros honores. Hasta donde sabemos, Servando Gómez de la Cortina recibió el título de conde de la Cortina y Pedro Alonso de Alles afirmó su posición política y social mediante la obtención de un cargo honorario. Por su parte, los hermanos Rábago y los Gómez de la Cortina, luego de haber mostrado su generosidad a las autoridades reales, fueron rehabilitados en términos políticos, lo que los posibilitó para acceder a los cargos de representación de la Universidad de mercaderes. Tanto en el caso de los negocios, como en el de los honores, pareciera que los contribuyentes de donativos y préstamos consiguieron mayores contraprestaciones al otorgar servicios financieros de manera individual. Esto parece ser indicativo del desarrollo de estrategias financieras para conseguir el favor del soberano.

Por lo que toca a los suplementos gratuitos que otorgaron los mercaderes dedicados a la producción agropecuaria, así como al suministro de ganado y granos a la capital, 
todo parece indicar que les garantizaron continuar participando como abastecedores de harina y otros víveres para alimentar a las tropas concentradas en la Habana. En cuanto al papel que desempeñó el Tribunal Mercantil como intermediario financiero de la Real Hacienda para conseguir el empréstito por millón de pesos, presumimos que, entre las compensaciones que obtuvo el cuerpo mercantil por este servicio, se encuentra el establecimiento del comercio libre de harinas con La Habana, el cual permitió sus miembros enfrentar la competencia de los angloamericanos que comerciaban harinas de mayor calidad a precios menores. Asimismo consiguió la supresión de las limitaciones impuestas a la introducción de cacao de Guayaquil por Acapulco. Además, es muy probable que, quienes entonces representaban al cuerpo mercantil también buscaran influir en las autoridades reales, tanto, para evitar el establecimiento del Reglamento de comercio libre en Nueva España, como para que se autorizara la reconstrucción del camino México-Veracruz por las rutas que favorecían sus negocios. Sin embargo, ambos temas tenían una importancia primordial en la política Imperial por lo que darían lugar a discusiones e investigaciones que prolongarían durante varios años la decisión real.

Cuando el Tribunal Mercantil buscó dinero para reunir el millón de pesos recibió ofertas muy superiores, podemos explicar este fenómeno, entre otras causas, por el dinamismo que entonces presentaba la economía novohispana, por la eficacia de las redes financieras que manejaban los principales miembros de la corporación y debido a las pocas oportunidades que había para invertir capitales a réditos de manera segura. No obstante, el Tribunal de Minería con grandes dificultades logró completar el millón de pesos requerido, por lo que tuvo que recurrir a su fondo dotal. Ambos cuerpos recibieron dinero de sujetos patriotas que buscaban una ganancia segura y se esforzaban por elevar su posición social mediante el reconocimiento real y la recepción de honores.

Con respecto a la colocación de los fondos que resguardaban los tribunales y juzgados eclesiásticos en el Depósito de caudales de la Casa de Moneda, el ministro de Indias tuvo que interceder en nombre del rey para vencer la resistencia del arzobispo de México. En cuanto a la creación de una nueva deuda mediante la recepción de caudales a censo a cuenta de la renta de tabaco, el virrey no logró que el poderoso arzobispo de México autorizara que se colocaran en la tesorería los fondos de obras pías y capellanías. Como alternativa se movilizaron las redes de los miembros del consulado, lo que permitió captar recursos de las hermandades piadosas y los conventos con los que estaban vinculados. Estos depósitos se restituyeron en diciembre del mismo año de 1783, debido al empeño del virrey en no gravar los fondos del real erario con el pago de réditos. En cambio, del empréstito negociado por el Tribunal del consulado de México únicamente se cubrieron 500,000 pesos a mediados de 1787, muy probablemente porque el pago de los intereses no recaía sobre la Real Hacienda.

Es importante recalcar que la mayor parte de los fondos extraordinarios para la guerra contra Gran Bretaña se obtuvieron en la capital del virreinato, en donde se concentraban el capital financiero, por ser la principal plaza de comercio y redistribución de mercancías, la sede de la única casa de moneda del virreinato, así como del resto de la administración civil y eclesiástica. También es necesario destacar que los miembros de la familia Castañiza-Bassoco contribuyeron con más de 500,000 pesos en donativos, suplementos, préstamos y depósitos para la guerra, lo que representó más del 10\% del 
total de los fondos captados. Las contribuciones de los Bassoco-Castañiza pueden entenderse por su espíritu patriótico, su interés en invertir fondos de manera redituable y segura, así como por su empeño en influir en las autoridades para que se reconstruyera el camino México-Veracruz por las rutas que favorecían sus principales negocios.

\section{REFERENCIAS BIBLIOGRÁFICAS}

AGN Archivo General de la Nación

AGI Archivo General de Indias

AHNCM Archivo Histórico de Notarías, México

AHH Archivo Histórico de Hacienda

BN Biblioteca Nacional, México

BNE Biblioteca Nacional de España

RAH Real Academia de la Historia, Madrid.

AndúJar Castillo, Francisco

2004 El sonido del dinero. Monarquía, ejército y venalidad en la España del Siglo XVIII. Madrid. Marcial Pons.

Bonialian, Mariano Ardash

2012 El Pacifico Hispanoamericano. Política y comercio asiático en el Imperio Español (1680-1784). México. El Colegio de México.

BöTTCHER, Nikolaus

2011 “Comerciantes británicos y el comercio interior de Cuba, 1762-1808”. En BÖTTCHER - HAUSBERGER - IBARRA (coords.), Redes y negocios globales en el mundo ibérico, siglos XVI-XVIII. Madrid. Iberoamericana - Vervuert, pp. 207-238.

BORCHART, Christian

1984 Los mercaderes y el capitalismo en la ciudad de México: 1759-1778. México. Fondo de Cultura Económica.

BRADING, David

1975 Mineros y comerciantes en el México borbónico (1763-1810). México. Fondo de Cultura Económica.

ChÁvez Orozco, Luis (compilación y prólogo)

1967 El contrabando y el comercio exterior en la Nueva España. México. Banco Nacional de Comercio Exterior.

Deans-Smith, Susan

1999 Bureaucrats, Planters, and Workers. The Making of the Tobacco Monopoly in Bourbon México. Austin. University of Texas Press, 1992.

GRAFENSTEIN, Johanna

1997 Nueva España en el Circuncaribe, 1779-1808. Revolución, competencia imperial y vínculos intercoloniales. México. Universidad Nacional Autónoma de México. 
Howe, Walter

1949 The mining guild of New Spain and its Tribunal general 1770-1821. Cambridge. Harvard University Press.

IrIGOIN, Alejandra - Grafe, Regina

2013 "Bounded Leviathan: Fiscal constraints and financial development in the Early Modern Hispanic world". En CofFMAn and LARRY (eds.), Question Credible Commitment: Perspectives on the Rise of Financial Capitalism. Macroeconomic policy making. Cambridge. Cambridge University Press, pp. 199227.

KLEIN, Herbert S.

1994 Las finanzas americanas del Imperio Español, 1680-1809. México. Instituto de Investigaciones Dr. José María Luis Mora - Universidad Autónoma Metropolitana-Iztapalapa.

KuETHE, Allan J.

1999 "El fin del monopolio: los Borbones y el Consulado andaluz". En VILA VILAR KUETHE (eds.), Relaciones de poder y comercio colonial: nuevas perspectivas. Sevilla. Escuela de Estudios Hispano-Americanos - Texas-Tech University, pp. 35-66.

MARICHAL, Carlos

1999 La bancarrota del virreinato. Nueva España y las finanzas del Imperio Español, 1780-1810. México. Fondo de Cultura Económica - El Colegio de México.

MurIEL, Josefina

1995 Conventos de monjas en la Nueva España. México. Editorial Jus.

Panes y Abellán, Diego de

1783 Descripción de los caminos que desde la plaza de Veracruz se dirigen a México por distintos rumbos. Ramales de caminos que se proponen por más rectos y cómodos. Cálculos prudenciales de costos y demás contenido en esta representación y en planos y perfiles separados, por Don Diego Panes y Abellan, Capitán del Real Cuerpo de Artillería y Comisionados por el Superior Gobierno de este reino. Veracruz, 20 de octubre de 1783.

Pérez Herrero, Pedro

1988 Plata y libranzas. La articulación comercial del México borbónico. México. El Colegio de México.

RAMíREZ, Santiago

1980 Datos para la historia del Colegio de Minería. Recogidos y compilados bajo la forma de efemérides por su antiguo alumno el ingeniero de minas Santiago Ramírez. México. Imprenta del Gobierno Federal en el Ex-Arzobispado, 1890.

Real Díaz, José Joaquín - Heredia, Antonia M.

1968 «Martín de Mayorga». En CALDERÓN QUIJANo (dirección y estudio preliminar), Los virreyes de Nueva España en el reinado de Carlos III. Sevilla. Escuela de Estudios Hispano-Americanos de Sevilla. Tomo II. 


\section{REGLAMENTO}

1979 Reglamento y aranceles reales para el comercio libre de España a Indias de 12 de octubre de 1778. Sevilla. Universidad de Sevilla - Escuela de Estudios Hispanoamericanos (CSIC).

Tepaske, John J. - Klein, Herbert S.

1986 Ingresos y egresos de la Real Hacienda de Nueva España. México. Instituto Nacional de Antropología e Historia (Colección Fuentes). 2 vols.

ToRres SÁnchez, Rafael

2013 El precio de la guerra. El Estado fiscal-militar de Carlos III (1779-1783). Madrid. Marcial Pons. Historia.

Valle Pavón, Guillermina

1997 El Consulado de comerciantes de la ciudad de México y las finanzas novohispanas, 1592-1827. (Tesis para optar al grado de doctor en historia). México. El Colegio de México.

2004 "El respaldo del Consulado de México para la Guerra de Sucesión Dinástica". En Acosta - GonzÁlez - Vila Vilar (eds.), La Casa de la Contratación y la navegación entre Sevilla y las Indias. Sevilla. Universidad de Sevilla - Consejo Superior de Investigaciones Científicas - Escuela de Estudios Hispanoamericanos - Fundación El Monte, pp. 941-964.

2007a "Los excedentes del ramo de alcabalas. Habilitación de la minería y defensa del monopolio de los mercaderes de México en el siglo XVIII". Historia Mexicana. México, vol. LVI, no 2, (223), enero-marzo, pp. 969-1016.

$2007 b$ "La articulación del mercado del centro, oriente, sur y sureste de Nueva a través del camino de Orizaba, en las postrimerías del siglo XVIII". En OIKION (ed.), Historia, Nación y Región. México. El Colegio de Michoacán, vol. II, pp. 437-460.

2010 "Antonio de Bassoco, empresario del consulado de México en una época de cambios", En Ludlow, 200 emprendedores mexicanos. La construcción de la Nación. México. Lid Editorial, vol. I, pp. 53-58.

2010 "Comercialización de cacao de Guayaquil por los mercaderes del Consulado de México en la segunda mitad del siglo XVIII". Mexican Studies - Estudios Mexicanos. Berkeley, vol. 26, nº 2, 2010, pp. 181-206.

2012 Finanzas piadosas y redes de negocios. Los mercaderes de la ciudad de México ante la crisis de Nueva España, 1804-1808. México. Instituto de Investigaciones Dr. José María Luis Mora.

2014 "Funciones crediticias de las cofradías y los negocios de los mercaderes de la ciudad de México, fines del siglo XVIII y principios del siglo XIX". Revista de Indias. Madrid, vol. LXXIV, nº 261, (mayo-agosto), pp. 507-538.

Wobeser, Gisela von

1994 El crédito eclesiástico en la Nueva España. Siglo XVIII. México. Universidad Autónoma de México. 